\title{
PROTOTYPE OF WEB-BASED DAILY WORK REPORT MANAGEMENT SYSTEM USING SMART PENS
}

\author{
Tim Chen', Alexander Babanin'2, Abū al-Qāsim Muhammad³, Bertrand Chapron ${ }^{4}$, John Chen ${ }^{5,6 *}$, \\ Himel Md Sakibul Hassan Sajib, \\ ${ }^{1}$ AI LAB, Faculty of Information Technology, Ton Duc Thang University, Ho Chi Minh City, Vietnam \\ ${ }^{2}$ University of Melbourne, Melbourne, Australia \\ ${ }^{3}$ King Abdulaziz University, Jeddah, Saudi Arabia \\ ${ }^{4}$ Laboratoire d'Océanographie Physique et Spatiale, Centre de Brest, IFREMER, Plouzané, France \\ ${ }^{5}$ Staffordshire University, Staffordshire, United Kingdom \\ ${ }^{6}$ BRAC University, Dhaka, Bangladesh \\ ${ }^{7}$ Asia Pacific University, Kuala Lumpur, Malaysia
}

As development plans become more complex, information about the means of implementation at the organizational stage becomes more and more important. However, spurious and informational experiments often occur when processing handwritten information. The construction project consists of compound entrepreneurs and subcontractors who have different technical and supervisory systems and need to communicate continuously by generating building information among shareholders. Therefore, this study will present a prototype of a web-based periodic records management system in which project stakeholders can participate in construction information using digital pen input on a web-based system. Based on the submitted system, this topic assumes the results of production efficiency, smooth transmission, and resource management. The result of this survey is to increase the fertility rate of buildings by providing a network-based daily reporting management system to construction sites.

Key words: Prototyping, Management system, Information technology, Construction.

\section{INTRODUCTION}

Current management system control frameworks join different components united with the end goal to achieve some objective utilizing spread interlocking bonds [1 - 5]. The more convoluted adaptation incorporates many hardware units included into one innovative process and working consequently [6 - 9]. These kinds of management system as construction projects become larger and more complex, and it has been more important to utilize information on the resources used at the construction phase, including materials, equipment and manpower. These pieces of information are also useful to manage the process of a construction project and the quantities of materials used in it. Moreover, they are also used as a reference in the planning and performance progress of subsequent construction projects to make it possible to manage a construction project efficiently. To do this, it is necessary to save and utilize the data of each construction project [10-12].

Information, most of it hand-written, is collected and processed from construction sites. Due to the nature of hand-written material, a great deal of time is required to compile the information gleaned from construction sites. In addition, the errors and loss of information that often arise in the course of hand-written information processing prevent the task from being carried out smoothly.

As such, many studies have been conducted in the construction field with the aim of achieving more efficient construction information management by improving the daily reporting methods. Lee and Son (2012) pointed out the problems of the daily work reporting method used by each construction company, and presented an improvement plan [13]. Shin et al. (2013) performed an analysis of the current operation state of daily work reporting methods of specialty construction companies [14]. However, the previous studies have limitations in that they presented the daily work reporting method only or suggested improvements for these.

A construction project is done by a group of multiple contractors and subcontractors that have different technologies and management systems, and smooth communication is needed through sharing the construction information among the participants. Thus, a new webbased daily work report management system is provided. Through the system, the project participants can share construction information entered using a digital pen on a web-based system.

The scope of this research is restricted to assessing the applicability of the web-based daily reporting system using a digital pen. To achieve this, applicability is evaluated by building a webbased daily work report management system. 


\section{DIGITAL PEN TECHNOLOGY}

\section{The composition of a digital pen}

The digital pen is seemingly similar to a general pen. However, as shown in Fig. 1, it is composed of an ink cartridge, an infrared camera, an image processor, a Bluetooth wireless communication device, memory and a battery. A document made with the digital pen can be saved in a database from the words and images of the original document. In addition, the digital pen can send the absolute coordinates of pen strokes, pen pressure on the sheet, the speed and time of the hand-writing, and the tilting angle of the pen, as well as the words or images.

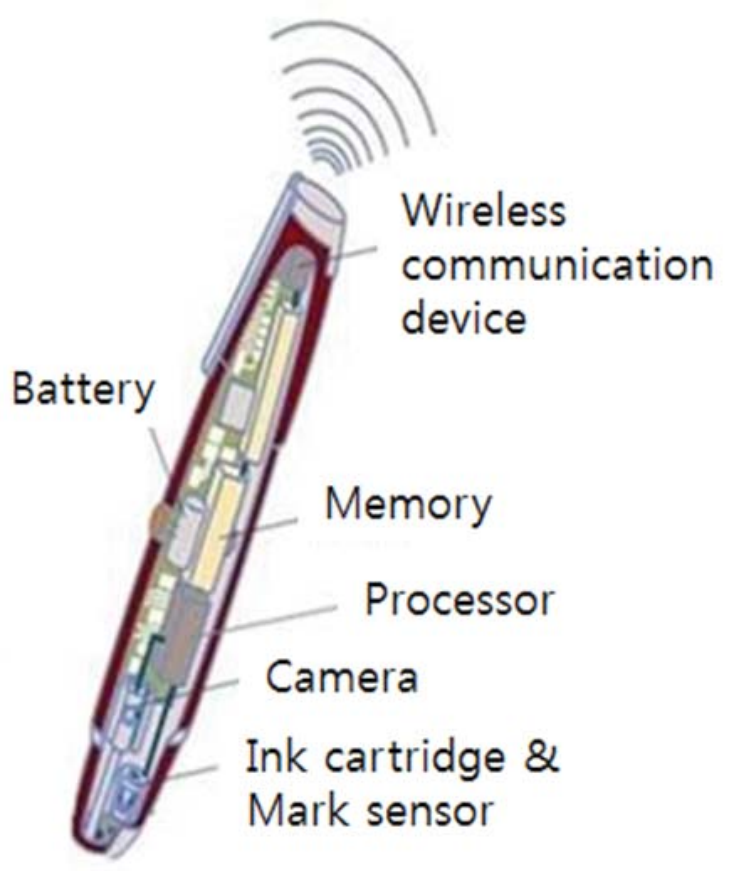

Figure 1: Composition of digital pen

\section{Action of the digital pen and data transmission mode}

Upon the detection of the contact of the pen on the sheet with pressure by the input sensor of the digital pen, the digital pen is activated to write. The digital camera takes about 100 frames per second. In addition, the imaging processor obtains the coordinates taken from the image to save them in memory as Pen Generated Coordinates (PGC) or in a bi-file image file format, and then send the data to the server.

The data transmission methods can be categorized into Bluetooth method and Universal Serial Bus (USB) connection method. When the Bluetooth method is used, the pen triggers an action through a wireless connection between the Bluetooth and the pen, and the pidget (a pattern page element that includes a logical meaning for the pen sent via Bluetooth) is identified and simultaneously sent through the digital pen. When the USB method is used, the data written by the digital pen is first saved in the memory and sent to the server en bloc based on the time basis taken to dock the pen on a PC (TABLE 1).

Table 1: Feature of data transmission mode

\begin{tabular}{|c|c|c|}
\hline Method & Bluetooth & USB \\
\hline Used machinery & Mobile & PC \\
\hline Connection & Pidget check & Cradle docking \\
\hline Transmission & Real time & Batch \\
\hline
\end{tabular}

\section{DEVELOPING OF A WEB-BASED DAILY REPORTING} MANAGEMENET SYSTEM

\section{Composition of the web-based daily report management system}

The web-based daily report management system is composed of Form Design Tool (FDT), a server, a client, and a digital pen. FDT makes it possible not only to generate Anoto-enabled documents but also to add components such as drawing areas, user areas and pidgets. In addition, FDT enables users to save files in a range of formats including PNG, PAD, and PS on the server as service information. The server generates the digital letter by recognizing the words handwritten on the user area and the digital image of the PGC data received from its clients. The clients are PC and mobile devices that receive and then transmit PGC data to the server via either a Bluetooth or a USB method. In the web-based daily work report management system, the hand-written information created by a digital pen in PGC format is saved in memory and transmitted to the server via a client.
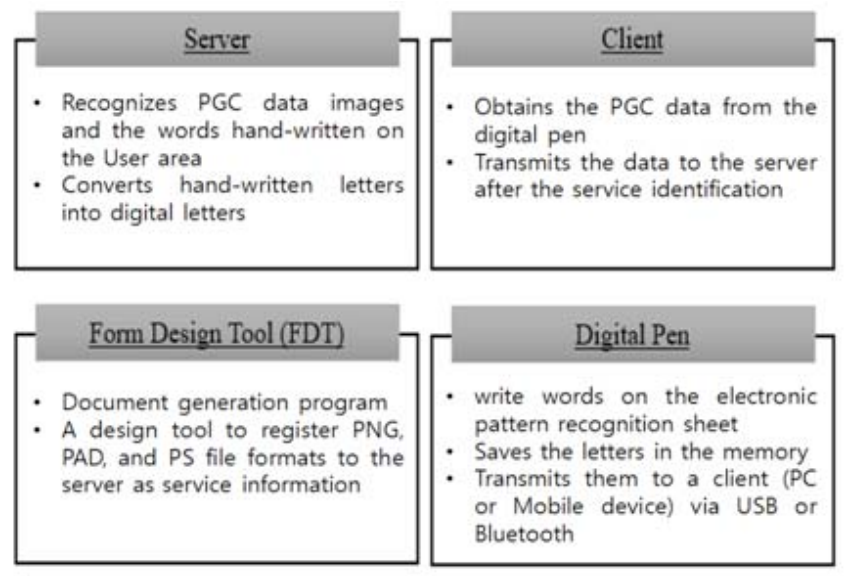

Figure 2: Structure of web-based daily work report management system 


\section{Daily reporting process at a construction site}

At a construction site, the work of the day is hand-written on the pattern-recognizable paper using a digital pen after the work is finished. On the daily reporting form, basic information and detailed information are entered. To be specific, the basic information includes the date, the construction site name, the construction company, and the entire processing rate, weather, and temperature, while the detailed information includes the work done in the day, the work type, the position of the work, the amount of the work done, the current state of the number of workers input, the current state of the equipment input, the current state of major materials and others.

The information entered is sent to the server via a mobile device through either Bluetooth or a USB method depending on the site condition. At a site that has the Internet connection, the digital pen is connected to a PC using a USB method to send the data to the server via a notebook or desktop PC. On the other hand, at a site that has no Internet connection, the data is sent to the server via a mobile device or the digital pen using Bluetooth through an LTE/3G communication network. On the server, the data can be seen on the web through a digital imaging process and handwriting recognition process by the daily work report management system. Data that has undergone the above processes is immediately sent to the server so that the user can check whether or not the daily report is digitized, and download the report in a file format or print it out, if necessary (Fig. 3).

\section{Anticipated effects}

The qualitative effects that can be obtained through the introduction of web-baseddaily work report management system using a digital pen can be summarized as follows:

- First, it will improve the work efficiency at a construction site with no additional effort required from the worker because the hand-written information is saved and sent to the web almost immediately.

- Second, it will make communication smoother since owner, designers, contractors and subcontractors participating in a construction project can share the information.

- Third, through the construction information acquired, it is possible to estimate how much work can be done per day, and the major resources can thus be managed more efficiently.

\section{CONCLUSIONS}

This study proposes a web-based daily work report management system, and the applicability of the system is also evaluated in a qualitative manner. The proposed system sends and saves the data on the server using a PC or mobile device via Bluetooth or a USB connection. The data can be checked anywhere an Internet connection is available, via a PC or a mobile device. Unlike the conventional system, which only utilized a PC, the webbased daily work report management system has

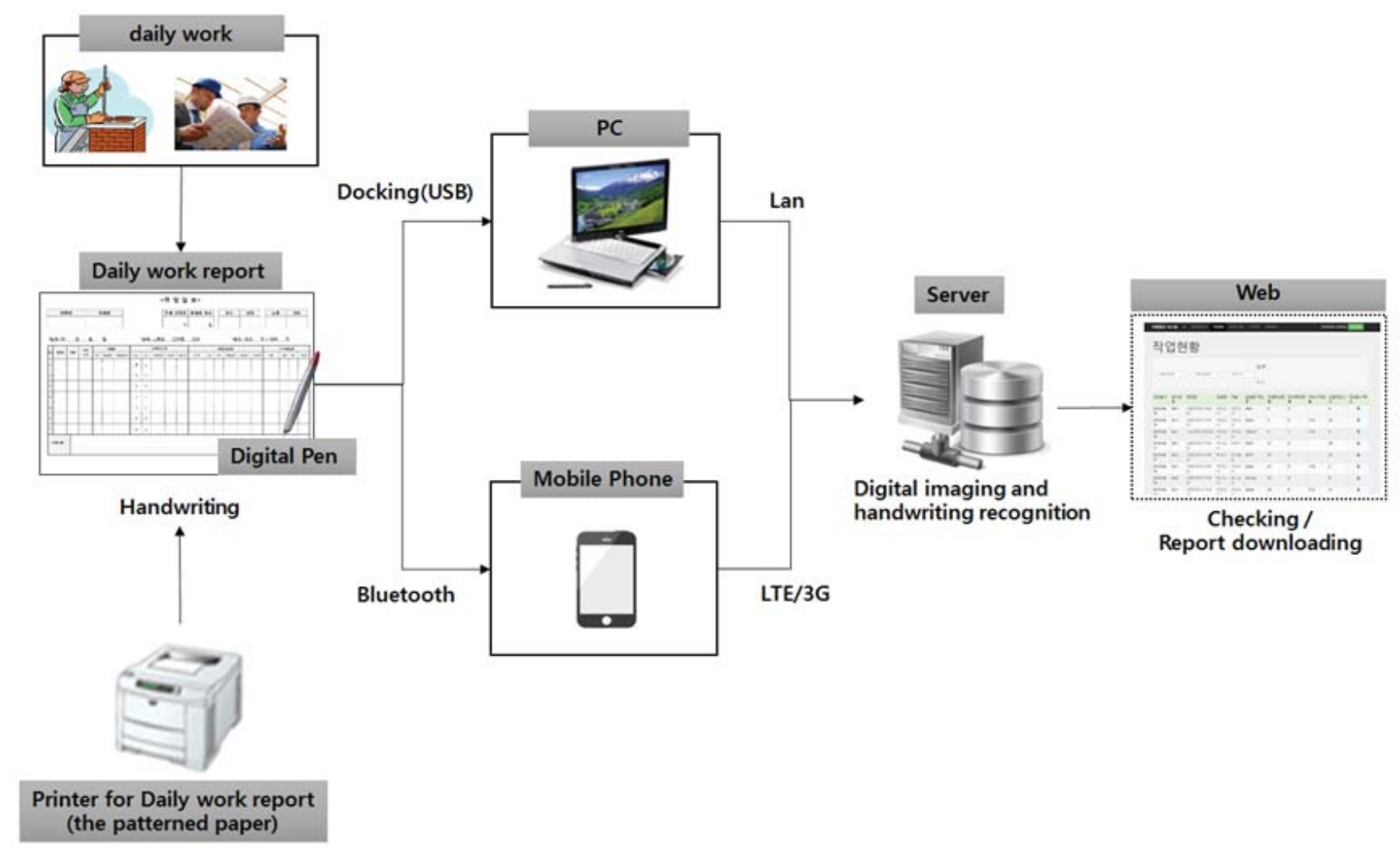

Figure 3: Work process of web-based daily work report management system 
an advantage in that the construction information can be shared in real-time among participants in a construction project. For this reason, it is anticipated that there will be qualitative improvements in the three areas of work efficiency, communication and resource management.

This study has a limitation in that the effects of the introduction of the proposed system were analyzed qualitatively. To improve the utilization of the proposed system at construction sites, each advantage should be presented based on a numerical effect. As such, future research should measure the construction work efficiency through a quantitative analysis by introducing the web-based daily work report management system to construction sites.

\section{REFERENCES}

1. Ostroukh, A.V. (2013). Systems of Artifi cial Intelligence in the Industry, the Robotics and the Transport Complex. Krasnoyarsk, RU: PublishingHouseScienceandInnovationCenter, Ltd.

2. Ostroukh, A.V. \&Surkova N.E. (2015). Intelligence Information Systems and Technologies.Krasnoyarsk, RU: Publishing House Science and Innovation Center, Ltd.

3. Ostroukh, A.V. \& Tian, Yu. (2014). Automated system for monitoring production-technological and organizational-economic activity of industrial enterprises. Instruments and Systems: Monitoring, Control, and Diagnostics, (3), 14-21.

4. Tian, Yu., Nguen, D.T., Chaudhary, R.R. \&Ostroukh, A.V. (2014). Automated monitoring production - technological and organizational - economic activities of an industrial enterprise. Automation and Control in Technical Systems, 3(1.2), 16-31. DOI: 10.12731/2306-15612014-1-16.

5. Ostroukh, A.V. \& Tian, Yu. (2013). Integration of monitoring system components. Young Scientist, 6(10), 182185.

6. Ostroukh, A.V. \& Tian, Yu. (2014). Development of the information and analytical monitoring system of technological processes of the automobile industry enterprise. In the World of Scientifi c Discoveries, Series B,2(1), 92102.
7. Gimadetdinov, M.K. \&Ostroukh, A.V. (2014). List and Sequence of Solutions for Automated Crushing and Screening Production. Automation and Control in Technical Systems, 3(4), 55-61. DOI: 10.12731/2306-15612014-4-6.

8. Vorobeva, A.V., Ostroukh, A.V. Gimadetdinov, M.K., Wai Phyo Aung \&Myo Lin Aung. (2015). Development of mathematical models and methods of optimal control of automated crushing and screening process. IndustriaIAutomaticControlSystemsandControllers, (1), 9-16.

9. Gimadetdinov, M.K., Popov, V.P. \&Ostroukh, A.V. (2015). Automation of Crushing and Screening Production with a Full Range of Technological Operations and Related Processes. Industrial Automatic Control Systems and Controllers, (9), 10-18.

10. Salniy, A.G., Kukharenko, V.N., Nikolaev, A.B.\&Ostroukh, A.V. (2013). General Principles of SCADA Design. AutomationandControlinTechnicalSystems, 2(2), 8-12.

11. Varlamov,O.O. (2015). Mivar Role and Place in Computer Sciences, Artifi cial Intelligence Systems and Informatics.Radio Industry,(3), 10-27.

12. Shadrin, S.S., Varlamov, O.O. \& Ivanov, A.M. (2017). Experimental Autonomous Road Vehicle with Logical Artifi cial Intelligence. Journal of Advanced Transportation. DOI:10.1155/2017/2492765.

13. Lee, D. E., Son,C. B. (2012). Improvement measures of daily work report for efficient enactment and/or revisionof construction standard production unit system. Journal of Architectural Institute of Korea, vol. 28, no. 5, 135-142.

14. Shin, W. S., Lee, D. E., Son,C. B. (2013). Analyzing the operational conditions on daily work report of specialty contractorsand its improvement measures. Journal of Architectural Institute of Korea, vol. 29, no. 11, 91-98. 